\title{
Brain Cell Karyotype of the Phlebotomine Sand Fly Lutzomyia shannoni (Dyar) (Diptera: Psychodidae)
}

\author{
María E Jiménez, Felio J Bello, Cristina Ferro*, Estrella Cárdenas*/+
}

Facultad de Ciencias de la Educación, Departamento de Química y Biología, Universidad de La Salle, Santa Fe de Bogotá, Colombia *Laboratorio de Entomología, Instituto Nacional de Salud, Avenida Eldorado, Carrera 50, Zona Postal 6, Apartado Aéreo 80080, Santa Fe de Bogotá, Colombia

The brain cell karyotype of New World sand fly Lutzomyia shannoni was described. This species has four pairs of chromosomes, $2 N=8$, with one pair of heteromorphic chromosomes.

Key words: Lutzomyia shannoni - brain cell karyotype - heteromorphic chromosome

Brain cell karyotypes of four Old World and eight New World sand flies were described and compared by Kreutzer et al. $(1987,1988)$. Among the eight New World sand flies species, the chromosome number varies from $2 \mathrm{~N}=6$ in Lutzomyia trapidoi to $2 \mathrm{~N}=8$ in the following species: $L$. gomezi, L. erwindonaldi, L. carmelinoi, L. walkeri, L. columbiana, L. spinicrassa, and L. longipalpis. Heteromorphic chromosomes were not observed in these species (Kreutzer et al. 1988). On the other hand, Yin et al. (1999) studied patterns of G-banding in mitotic karyotypes in populations of $L$. longipalpis and found ancestral patterns in the populations. This paper provides preliminary data of cytogenetic studies of New World sand fly $L$. shannoni.

Fourth instar larvae were obtained from a $L$. shannoni colony maintained since 1992 in the Entomology Laboratory of Instituto Nacional de Salud of Colombia, and originated from collections in the Lower Magdalena Valley. The techniques used for rearing the sand fly followed standard protocols in our laboratory. The larval diet was made with bovine manure and dog food; this mixture was stored for three months and stirred every two weeks. The females were fed on hamster blood (Ferro et al. 1998). The brain cell slides

\footnotetext{
This research was supported by Colciencias (grant no. 2104-04-179-95), Universidad de La Salle and Instituto Nacional de Salud de Colombia.

${ }^{+}$Corresponding author. Fax: +57-1-315.7341. E-mail: ecardenas95@latinmail.com

Received 27 June 2000

Accepted 5 September 2000
}

of larvae were prepared by the procedures of Bhat and Modi (1976) and Kreutzer et al. (1987). The larvae were placed in $0.1 \%$ colchicine for $4 \mathrm{~h}$; then the heads of larvae were removed and placed in a $2 \%$ orcein stain for $10 \mathrm{~min}, 25 \mathrm{ml}$ glacial acetic acid, and $25 \mathrm{ml} 85 \%$ lactic acid. After staining, the heads were placed in a small drop of $50 \%$ acetic acid on a microscope slides. The contens of the head capsule were removed by pressure. Then the pieces of the head capsule were discarded and the small drop of stain was added. The cover slide was placed on the slide and the tissue was squashed in folded filter paper to absorb excess stain/acid. The slides were photographed with an Olympus microscope system at 1000X. Forty slides were examined, each containing from 3 to 12 karyotypes. The chromosomes were identified according to relative size and centromere position (Sessions 1996).

As reported by Bello et al. (1997) the complement is eight chromosomes for L. shannoni (Fig. 1A). We observed several karyotypes with one pair, chromosome I, as heteromorphic (Fig. 1B) and probably an $\mathrm{X}$ and $\mathrm{Y}$ chromosome. Determination of the sex of the larvae was not possible before dissection. Chromosomes I, III and IV were metacentric, whereas chromosome II was submetacentric. This karyotype was similar to that of $L$. spinicrassa except that in this species the heteromorphic chromosome was not observed (Kreutzer et al. 1987).

Only in Old World sand fly Phlebotomus perniciosus has been reported with a pair of chromosome heteromorphic (Kreutzer et al. 1987). The pair of chromosome heteromorphic observed in $L$. shannoni and $P$. perniciosus suggest the presence of sex chomosomes in other species of the genera Lutzomyia and Phlebotomus. 

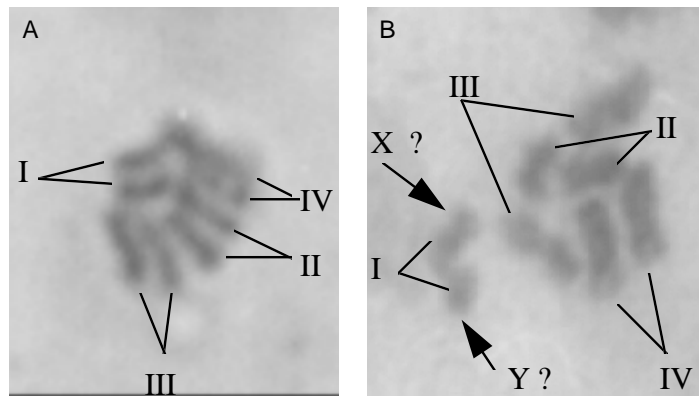

Fig. 1: metaphase mitotic chromosomes of Lutzomyia shannoni from brain cells, 1000X. A: homomorphic karyotype female; B: heteromorphic karyotype male

\section{REFERENCES}

Bhat UKM, Modi GB 1976. Karyotype of the sand fly Phlebotomus papatasi. Curr Sci 45: 265-266.

Bello FJ, Jiménez ME, Ferro C 1997. Cultivos celulares primarios de Lutzomyia shannoni (Diptera: Psychod- idae) y estudio cariológico preliminar de la especie. Biomédica 17: 49-55.

Ferro C, Cárdenas E, Corredor D, Morales A, Munstermann LE 1998. Life cycle and fecundity analysis of Lutzomyia shannoni (Dyar) (Diptera: Psychodidae). Mem Inst Oswaldo Cruz 93: 195-199.

Kreutzer RD, Modi GB, Tesh RB, Young DG 1987. Brain cell karyotypes of six species of New and Old World sand flies (Diptera: Psychodidae). J Med Entomol 24: 609-612.

Kreutzer RD, Morales A, Cura E, Ferro C, Young DG 1988. Brain cell karyotypes of six species of New World sand flies (Diptera: Psychodidae). J Am Mosquito Contr Assoc 4: 453-455.

Sessions SK 1996. Chromosomes: molecular cytogenetics. In DM Hills, C Moritz, BK Mable (eds), Molecular Systematics, Sinauer Associates, Inc., Sunderland, MA, $655 \mathrm{pp}$.

Yin H, Mutebi JP, Marriott S, Lanzaro GC 1999. Metaphase karyotypes and G-banding in sandflies of the Lutzomyia longipalpis complex. Med Vet Entomol 13: 72-77. 